\title{
Weight change, perceived health status and mortality in middle-aged British men
}

\author{
Goya Wannamethee and A.G. Shaper
}

Department of Public Health and Primary Care, Royal Free Hospital School of Medicine, Rowland Hill Street, London NW3 $2 P F, U K$

Summary: The association between weight change over a 5-year period, the subsequent perception of health and the mortality during a 4-year follow-up period has been examined in a prospective study of 7735 middle-aged British men. There were 357 deaths from all causes. Self-assessment of health status was considered as a potential guide to whether weight loss was intended or involuntary. Irrespective of weight change those who reported poor or fair health had a more than two-fold increase in death rate compared to those who reported good or excellent health. Considerable weight gain $(>10 \%)$ was associated with high rates of cardiovascular disease regardless of health perception, although this was most marked in those who perceived poor or fair health. Moderate weight gain was of little importance except in those who regarded their health as poor or fair. Weight loss was associated with increased death rates from cancer regardless of health perception, although the rates were highest in those who perceived poor or fair health.

This study emphasizes that weight loss is a potentially serious symptom even in men who report good health. Assessment of weight change and of perception of health status are both of value and could be used in standard health enquiries to monitor health status in individuals and the community.

\section{Introduction}

In the majority of studies that have examined the relationship between body weight and mortality, both lean people and overweight people show an increased risk of mortality. ${ }^{1}$ In a previous report from the British Regional Heart Study we have shown that a substantial weight gain in middleaged men ( $>10 \%$ increase in body weight), even without becoming obese $\left(\geqslant 28 \mathrm{~kg} / \mathrm{m}^{2}\right)$, was associated with an increased risk of cardiovascular mortality and that weight loss $(\geqslant 4 \%)$ of any degree was associated with increased mortality largely associated with cancer. ${ }^{2}$ Weight loss may be intentional or involuntary; weight gain is almost always involuntary - few people set out to gain weight deliberately. Perception of health has been shown to be a good indicator of health status and may play an important role in individual diagnosis. ${ }^{3}$ Several studies have shown a strong correlation between perceived health status and objective measurements of health. ${ }^{4,5}$

This paper examines weight change in middleaged British men over a 5 -year period and the association between perception of health and mortality during the subsequent four years. We hypothesized that self-assessment of health status might

Correspondence: Professor A.G. Shaper, F.R.C.P., F.R.C.Path.

Accepted: 21 June 1990 be a guide to whether weight loss was intended or involuntary and have examined our data with this hypothesis in mind. At the same time, we have examined perception of health in those who gained weight in order to see whether the outcome in terms of mortality might be related to the patients' perception of their health status.

\section{Subjects and methods}

In 1978-80, 7735 men aged 40-59 were selected at random from general practices in 24 towns in England, Wales and Scotland for a prospective study of cardiovascular disease (The British Regional Heart Study; BRHS). The criteria for selecting the town, general practice and the subjects as well as the methods of data collection have been reported. ${ }^{6}$ Research nurses administered to each man a standard questionnaire $(\mathrm{Q} 1)$ which included questions on smoking habits, alcohol intake and medical history. A number of physical measurements, including height and weight, were made and blood was taken for measurement of biochemical and haematological variables.

Five years later (1983-1985), a similar questionnaire (Q5) was sent to all surviving men and detailed information obtained on changes in smoking behaviour, present and past drinking habits, medical history and employment status. The men 
were asked 'How would you describe your health at present? - excellent, good, fair or poor.' The men were asked about weight change and to report their current weight. This report is concerned with the 7275 men, $98 \%$ of available survivors, who completed the fifth-year questionnaire.

Body mass index (BMI) calculated as weight/ height ${ }^{2}\left(\mathrm{~kg} / \mathrm{m}^{2}\right)$ was used as an index of relative weight. At initial screening each man was weighed in trousers and socks to the nearest $0.1 \mathrm{~kg}$ on an MPS110 field survey scale (beam balance) and height was measured without shoes to the nearest millimetre, using a Harpenden Stadiometer with digital meter. Five years later the men were asked to state their weight in pounds or kilograms and BMI was calculated for each man based on their reported weight and on measured height at prior screening.

\section{Results}

During the mean follow-up time of 4 years after the fifth year questionnaire there were 357 deaths from all causes. Of these, 173 were cardiovascular (49\%), comprising 145 ischaemic heart disease, 16 stroke and 12 other cardiovascular causes, and 184 were non-cardiovascular including 138 cancer deaths $(39 \%)$. Data on weight change were not provided by 19 men who died. The average weight was $76.6 \mathrm{~kg}$ at screening and $77.7 \mathrm{~kg}$ five years later. The average BMI at screening was $25.5 \mathrm{~kg} / \mathrm{m}^{2}$ (standard deviation 3.37 ) rising to $25.82 \mathrm{~kg} / \mathrm{m}^{2}$ (s.d. 3.21) 5 years later.

\section{Measures of weight change}

Absolute weight change ranged from $-42 \mathrm{~kg}$ to $+44 \mathrm{~kg}$ with a mean of $1.02 \mathrm{~kg}$ (s.d. 4.74). An index for weight change was determined for each man, calculated as the percentage change in body weight since initial screening. For a man of average weight $(76 \mathrm{~kg})$ it was arbitrarily considered that a loss or gain of $3.0 \mathrm{~kg} \mathrm{(4 \% )}$ would constitute a change in weight. Those with weight loss were defined as men who had lost at least $4 \%$ in body weight; weight gain was defined as those who had gained $4 \%$ or more in body weight. Those who had gained or lost less than $4 \%$ in body weight were classified as 'stable'. The men were classified into 4 groups: (1) those who had lost weight, (2) those who were stable, (3) those who had gained $4-10 \%$ in body weight and (4) those who had gained more than $10 \%$ in body weight. There were too few men with weight loss $>10 \%$ to constitute a separate category. Over half of the men $(55 \%)$ had little or no change in weight since screening, $31 \%$ had gained weight and $14 \%$ had lost weight (Table I).

\section{Weight change, perceived health status and mortality}

The distribution of the self-assessment of health status is shown in Table I. Men who had lost weight or who had gained substantial weight $(>10 \%)$ had the highest proportion of men who regarded their health as poor, $4.9 \%$ and $4.7 \%$ respectively, compared to $2-3 \%$ among other men. In order to assess whether the association between weight change and mortality was related to perception of health, and in particular to try and distinguish intentional weight loss from involuntary weight loss probably associated with disease, we have subdivided each weight change category into two groups: those who assessed their health as poor or fair and those who assessed their health as good or excellent (Figure 1). Men who lost weight and perceived their health as poor or fair are considered to represent a group whose weight loss may be involuntary. The mortality rates shown have been adjusted for age and smoking at screening. First, because those who perceived poor or fair health

Table I Percentage of men in each weight change category according to their perceived health status $(\%)$. Number of men in brackets.

\begin{tabular}{|c|c|c|c|c|c|}
\hline \multirow{2}{*}{$\begin{array}{l}\text { Change in } \\
\text { body weight }\end{array}$} & \multirow[b]{2}{*}{ No. of men } & \multicolumn{4}{|c|}{ Perceived health status } \\
\hline & & Excellent & Good & Fair & Poor \\
\hline Loss & $990(14 \%)$ & $\begin{array}{l}18.7 \\
(185)\end{array}$ & $\begin{array}{l}51.6 \\
(511)\end{array}$ & $\begin{array}{l}24.9 \\
(246)\end{array}$ & $\begin{array}{l}4.9 \\
(48)\end{array}$ \\
\hline Stable & $3885(55 \%)$ & $\begin{array}{l}22.5 \\
(872)\end{array}$ & $\begin{array}{c}57.3 \\
(2226)\end{array}$ & $\begin{array}{l}18.4 \\
(715)\end{array}$ & $\begin{array}{l}1.9 \\
(72)\end{array}$ \\
\hline Gain $4-10 \%$ & $1690(24 \%)$ & $\begin{array}{l}21.3 \\
(360)\end{array}$ & $\begin{array}{l}56.0 \\
(947)\end{array}$ & $\begin{array}{l}19.8 \\
(335)\end{array}$ & $\begin{array}{l}2.8 \\
(48)\end{array}$ \\
\hline Gain $>10 \%$ & $473(7 \%)$ & $\begin{array}{l}14.2 \\
(67)\end{array}$ & $\begin{array}{l}51.6 \\
(244)\end{array}$ & $\begin{array}{l}29.6 \\
(140)\end{array}$ & $\begin{array}{l}4.7 \\
(22)\end{array}$ \\
\hline & 7038 & $\begin{array}{c}21.1 \\
(1484)\end{array}$ & $\begin{array}{c}55.8 \\
(3928)\end{array}$ & $\begin{array}{c}20.4 \\
(1436)\end{array}$ & $\begin{array}{c}2.7 \\
(190)\end{array}$ \\
\hline
\end{tabular}




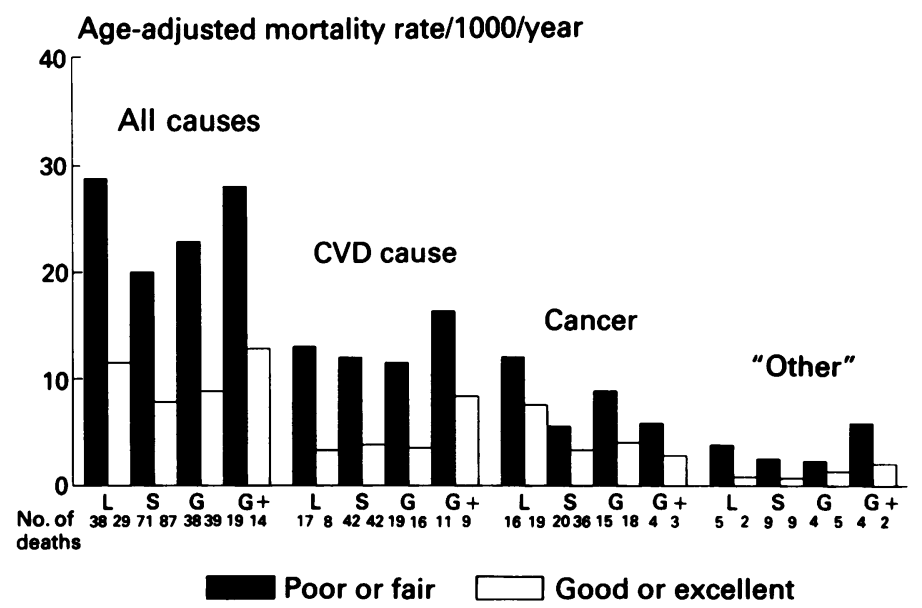

Figure 1 Mortality rates for all causes, cardiovascular disease (CVD), cancer and 'other' causes by weight change, in men who reported excellent or good health and in men who reported fair or poor health. The mortality rates have been adjusted for age and smoking at screening. $L=$ loss of weight; $S=$ stable; $G=$ gain $4-10 \% ; G+=g a i n>10 \%$.

were significantly older than those who perceived good or excellent health (mean age 51.9 vs 49.7). Second, because in a previous report we have shown a strong association between weight change and smoking, weight gain being associated with giving up smoking. ${ }^{2}$ The proportion of smokers at screening was highest in those who subsequently gained weight and was lowest in those whose weight was stable. Within all weight change groups, those who perceived poor or fair health had a significantly higher proportion of smokers at screening than those who perceived good or excellent health $(53 \%$ vs $36 \%)$.

Irrespective of weight change, men who considered their health to be poor or fair had a higher mortality rate than those who felt good or excellent; relative risk $2.5 ; 95 \%$ confidence intervals 2.0-3.0 (Figure 1). This was seen for cardiovascular disease, cancer and 'other' causes. For all causes, those with weight loss who felt good or excellent had much lower death rates than those whose weight had been stable and considered their health poor or fair. However, they had slightly higher rates than the men who were stable and perceived good or excellent health, due to a higher rate of cancer in those with weight loss. For cancer, weight loss regardless of health perception was associated with increased rates of death compared with those whose weight was stable, although this was most marked for those who had lost weight and considered their health to be poor or fair. For weight loss with poor/fair perception of health the relative risk of death compared with the stable group with good/excellent health perception was 3.9 (CI 2.6-5.8). Even those who reported loss of weight but perceived good or excellent health had a
2.5 fold increase in risk of cancer (CI 1.4-4.4) compared to those whose weights were stable and reported good health. The former group had a slightly higher risk (1.4) than even those with stable weight who reported poor health. High rates of cardiovascular deaths were seen in those with gain of more than $10 \%$ in body weight irrespective of health perception although the rates were highest in those who considered their health to be poor or fair. Compared to those whose weight was stable and reported good health the relative risk of weight gain $>10 \%$ was 2.2 (CI $1.0-4.1)$ and 3.9 (CI 1.9-7.8) for weight gain $>10 \%$ who perceived good/excellent health and those who perceived poor/fair health respectively.

\section{Discussion}

In the present study perception of health is a good indicator of mortality outcome. Those who perceived poor or fair health had greater than a two-fold increase in death rate over a 4-year period of follow-up, irrespective of any weight change. Several studies have shown a strong correlation between perceived health status and objective measures of health. ${ }^{3}$ The findings of higher mortality associated with poorer perception of health has been found in other studies. ${ }^{7,8}$

Weight change was significantly associated with health perception, in particular weight loss and substantial weight gain were associated with higher rates of perceived poor or fair health (Table I). This association is consistent with the suggestion that weight loss often reflects underlying ill-health and that considerable weight gain is often associated 
with increased morbidity. When weight change was examined in relation to mortality with respect to perception of health it was seen that moderate weight gain (4-10\%) was of little importance over this period of time except in those who felt poor or fair. Substantial weight gain, regardless of health perception, was associated with high rates of cardiovascular disease and this was most marked in those who perceived poor or fair health. This indicates that gaining substantial weight even in later adult life may be a danger sign and is not a benign process, irrespective of self-perception of health. In a recent report from a large prospective study of 111,886 US women ${ }^{9}$ it was found that substantial weight gain (more than $10 \mathrm{~kg}$ ) during adulthood was strongly associated with an increase in risk of coronary heart disease, even after taking into account potential confounding factors. Our data and the findings from this US study clearly emphasize the importance of weight gain in both men and women in middle-age. Attention should be paid to people who gain substantial weight even

\section{References}

1. Wannamethee, G. \& Shaper, A.G. Body weight and mortality in middle-aged British men: impact of smoking. $\mathrm{Br} \mathrm{Med} J$ 1989, 299: $1497-1502$.

2. Wannamethee, G. \& Shaper, A.G. Weight change in middleaged British men: implications for health. Eur J Clin Nutr 1990, 44: 133-142.

3. Kaplan, S.H. Patient reports of health status as predictors of physiologic health in chronic disease. J Chronic Dis 1987, 40: $27 s-35 s$.

4. Leavy, R. \& Wilkin, D. A comparison of two survey measures of health status. Soc Sci Med 1988, 27: 269-275.

5. Hunt, S.M., McKenna, S.P., McEwen, J., Backett, E.M., Williams, J. \& Papp, E. A quantitative approach to perceived health status: a validation study. $J$ Epidemiol Community Health 1980, 34: 281-286.

6. Shaper, A.G., Pocock, S.J., Walker, M., Cohen, N.M., Wale, C.J. \& Thomson, A.G. British Regional Heart Study: cardiovascular risk factors in middle-aged men in 24 towns. Br Med J 1982, 283: 179- 186. if good health is reported. Weight loss is very often a diagnostic problem. ${ }^{10}$ Weight loss in those who perceived good or fair health was not associated with high rates of cardiovascular disease or noncancer ('other') causes. However, the finding that weight loss, regardless of health perception, is associated with increased rates of cancer death indicates that weight loss even in those who report good health is a potentially serious symptom. Our initial hypothesis that perception of health status may distinguish voluntary weight loss from weight loss probably associated with disease was not supported by the findings. It is therefore important to further evaluate the health in such subjects even when they report good health.

\section{Acknowledgements}

The British Regional Heart Study is a British Heart Foundation Research Group and is also supported by the Department of Health and The Chest, Heart and Stroke Association.

7. Kaplan, G.A. \& Camacho, T. Perceived health and mortality: a nine year follow-up of the human population laboratory cohort. Am J Epidemiol 1983, 117: 292-304.

8. Mossey, J. A. \& Shapiro, E. Self-rated health: a predictor of mortality among the elderly. Am J Public Health 1982, 72: 800-807.

9. Manson, J.E., Colditz, G.A., Stampfer, M.J. et al. A prospective study of obesity and risk of coronary heart disease in women. N Engl J Med 1990, 322: 882-889.

10. Marton, K., Sox, H.C. \& Krupp, J.R. Involuntary weight loss: diagnostic and prognostic significance. Ann Intern Med 1981, 95: 568-574. 